\title{
Loss of Cell-Cell Contact Is Induced by Integrin-Mediated Cell-Substratum Adhesion in Highly-Motile and Highly-Metastatic Hepatocellular Carcinoma Cells
}

\author{
Takuya Genda, Michiie Sakamoto, Takafumi Ichida, Hitoshi Asakura, and \\ Setsuo Hirohashi
}

Pathology Division (TG, MS, SH), National Cancer Center Research Institute, Tokyo; and The Third Department of Internal Medicine (TG, TI, HA), Faculty of Medicine, Niigata University, Niigata, Japan

\begin{abstract}
SUMMARY: The cadherin-mediated cell-cell adhesion system plays a critical role in normal development and morphogenesis. Inactivation of this system is thought to be responsible for cancer invasion and metastasis. A human hepatocellular carcinoma (HCC) cell line, KYN-2, was observed to have great potential for intrahepatic metastasis when orthotopically implanted into the liver of SCID mice. In vitro cultures of KYN-2 cells showed that they formed trabecular structures in suspension but lost tight cell-cell adhesion and became scattered when attached to a substratum such as collagen or fibronectin. In response to adhesion to the substratum, subcellular colocalization of E-cadherin and actin filaments were shown to be reduced, and a significant amount of $\alpha$-catenin was dissociated from the E-cadherin-catenin complex in KYN-2 cells. These changes of cell-cell adhesion were blocked by inhibitory monoclonal antibodies against $\beta 1$ and $\beta 5$ integrins. We found that c-Src was coimmunoprecipitated with E-cadherin-catenin complex and was tyrosine-dephosphorylated and activated in the adherent cells. The tyrosine dephosphorylation of c-Src was induced by cell adhesion to the substratum and inhibited by addition of inhibitory monoclonal antibodies against $\beta 1$ and $\beta 5$ integrins. These findings indicate that integrin-mediated cell-substratum adhesion inhibits cadherin-mediated cell-cell adhesion, possibly through c-Src activation, and suggest that this cross-talk mediates transient inactivation of the cadherin system and plays an important role in intrahepatic metastasis of human HCC. Modulation of this interaction might provide a new approach to prevent metastasis and recurrence of HCC. (Lab Invest 2000, 80:387-394).
\end{abstract}

$M$ etastasis to other parts of the liver through tumor cell dispersal via the portal vein is a common feature of human hepatocellular carcinoma (HCC) (Nakashima, 1976). This intrahepatic metastasis is observed more frequently than extrahepatic metastasis at a relatively early stage of the disease. It is one of the main causes of recurrence within the liver after initial treatment and for the poor prognosis of HCC patients (Nagao et al, 1990; Yuki et al, 1990).

Recently we constructed models of intrahepatic metastasis using orthotopic implantation of human $\mathrm{HCC}$ cell lines and identified the critical features of HCC cell lines with high metastatic potential (Genda et al, 1999). The highly-metastatic HCC cell lines showed high motility in vitro, mediated by small guanosine triphosphatase Rho and its downstream effector, Rhoassociated kinase, through actin reorganization. Inhi-

Received November 8, 1999.

This work was supported by a Grant-in-Aid for the Second Term Comprehensive 10-Year Strategy for Cancer Control from the Ministry of Health and Welfare of Japan. T.G. is a recipient of a Research Resident Fellowship from the Foundation for Promotion of Cancer Research (Tokyo, Japan). Address reprint requests to: Dr. S. Hirohashi, Pathology Division, National Cancer Center Research Institute, 5-1-1 Tsukiji, Chuo-ku, Tokyo 1040045, Japan. Fax: 8133248 2737.E-mail: shirohas@gan2.res.ncc.go.jp bition of cell motility resulted in prevention of intrahepatic metastasis in vivo, indicating that intrahepatic metastasis of $\mathrm{HCC}$ is critically regulated by the motility of cancer cells. Rapid and dynamic alterations of the actin cytoskeleton are observed in motile cells; for example, disruption of cortical actin bundles or stress fibers and formation of filopodia or lamellipodia. These structures of actin filaments are linked via cytoplasmic proteins to transmembrane adhesion molecules, such as CD44, cadherins, or integrins, and the activity of these adhesion molecules is regulated through this multimolecular complex. Cell adhesiveness to other cells or the substratum via this complex is thought to play important roles in cancer invasion and metastasis; however, the regulation of these adhesion molecules in motile cells is poorly understood, especially in epithelial cells.

In the present study we investigated the in vitro morphological features of $\mathrm{KYN}-2$, a highly-metastatic and highly-motile $\mathrm{HCC}$ cell line. KYN-2 cells attached tightly to each other and formed trabecular structures in suspension culture; however, they lost tight cell-cell adhesiveness and scattered in response to cellsubstratum adhesion. Using this $\mathrm{KYN}-2$ system, we examined the regulation of the cadherin-mediated cell adhesion system in motile cells and found that 
$\alpha$-catenin dissociation from the cadherin-catenin complex was induced by signals from the integrinmediated cell-substratum adhesion during cell scattering. Because this morphological alteration in vitro appeared to correspond to cancer cell dissociation from the primary cancer nest in vivo, our results suggest that cross-talk between cell-cell and cellsubstratum adhesion is involved in intrahepatic metastasis of human HCC and that modulation of this interaction might provide a new approach for preventing metastasis and recurrence of HCC.

\section{Results}

\section{Morphological Features of KYN-2 Cells In Vitro}

KYN-2 formed liver tumors after injection into the livers of severe combined immunodeficient (SCID) mice. Many small lesions were observed around the primary tumors, indicating that $\mathrm{KYN}-2$ cells have great potential for intrahepatic metastasis in vivo. Histologically these tumors were poorly differentiated HCCs showing thick trabecular structures. Tumor invasion into the portal vein and formation of tumor thrombi were frequently observed. The tumors showed marked destruction of trabecular structures and infiltrative growth at the tumor periphery both at sites of injection and metastasis (Genda et al, 1999).

Histologically, HCC consists of trabecular nests of cancer cells and a stroma formed of blood-containing sinusoid-like spaces, making them resemble cancercell islands suspended in the sinusoid-like blood spaces. The in vitro morphology of $\mathrm{KYN}-2$ cells in suspension culture was examined using phasecontrast microscopy. To prevent cell attachment to the substratum and keep the cells in suspension, KYN-2 cells were plated on tissue culture dishes that had been coated with polyhydroxyethylmethacrylate (polyHEMA), which prevents matrix deposition and cell attachment through its uniformly nonionic nature. One hour after being plated on polyHEMA, the KYN-2 cells began to adhere to each other and formed loose cell aggregations. Compact cell aggregation and large trabecular structures were observed after 36 to 48 hours (Fig. 1A), mimicking the thick trabecular structures seen in vivo. On the other hand, when KYN-2 cells adhered to a substratum such as collagen or fibronectin, they lost their tight intercellular contacts, formed lamellipodia at the cell edges, and became scattered, showing high motility (Fig. 1B) and mimicking the infiltrative growth of $\mathrm{KYN}-2$ cells at the periphery of tumors in vivo.

\section{Loss of Cell-Cell Contact Induced by Integrin-Mediated Cell-Substratum Adhesion}

To analyze the alteration of cell-cell adhesion molecules, we examined the expression of adherence junction components by immunocytochemistry (Fig. 2). In suspended cells, signals of E-cadherin and $\beta$-catenin (data not shown) were positive along sites of cell-cell adhesion, and actin filaments formed cortical actin bundles. These molecules were shown to colo- calize on the cell membrane and establish tight cellcell adhesion. In adherent cells, dense filamentous actin accumulated at the leading edge, forming membrane ruffling. E-cadherin and $\beta$-catenin signals were present diffusely in the cytoplasm and faintly on the cell membranes. Little colocalization of these molecules was observed in adherent cells.

The adhesive activity of cadherin is regulated by catenins, which link cadherins to actin filaments ( $\mathrm{Na}$ gafuchi and Takeichi, 1988). To assess the association of E-cadherin with catenins, immunoprecipitates collected with anti-E-cadherin antibodies were analyzed by immunoblot analysis (Fig. 3A). The amounts of $\beta$-catenin and plakoglobin associated with E-cadherin showed no difference between suspended and adherent cells, whereas the amount of $\alpha$-catenin in the complex was significantly reduced in adherent cells. Similarly, analysis of immunoprecipitates collected with anti- $\alpha$-catenin antibodies showed that the amount of E-cadherin associated with $\alpha$-catenin was reduced in adherent cells (Fig. 3B). Immunoblot analysis of whole-cell lysates showed that there was almost no difference in the amount of E-cadherin, $\beta$-catenin, plakoglobin, or p120CAS between the suspended and adherent cells, whereas expression of $\alpha$-catenin was reduced in the adherent cells compared with suspended cells (Fig. 3C).

It is known that many of the interactions between cells and the substratum are mediated by the integrin family of cell surface receptors (Juliano and Haskill, 1993). Therefore, the role of integrin-mediated cell adhesion in modulation of cell-cell contacts in KYN-2 cells was elucidated using inhibitory monoclonal antibodies against $\beta 1$ and $\beta 5$ integrins, because these integrins are expressed in $\mathrm{KYN}-2$ cells and inhibitory antibodies against these integrins suppress adhesion and spread of $\mathrm{KYN}-2$ cells on collagen or fibronectin in the presence of $10 \%$ fetal calf serum (data not shown). Addition of inhibitory antibodies to the culture medium inhibited cell spreading and membrane ruffling, and cell compaction was observed (Fig. 1C). E-cadherin, catenins, and actin filaments were observed immunocytochemically to colocalize at sites of cell-cell contact (data not shown). Nonimmunized mouse IgG did not induce morphological alteration of $\mathrm{KYN}-2$ cells cultured on collagen-coated dishes (data not shown). Dissociation of $\alpha$-catenin from the cadherin-catenin complex was also inhibited by addition of inhibitory antibodies (Fig. 3D). These results indicate that inactivation of the cadherin-mediated cell adhesion system was induced by integrin-mediated cellsubstratum adhesion in $\mathrm{KYN}-2$ cells.

\section{Activation of C-Src Kinase and Its Association with the Cadherin-Catenin Complex}

Tyrosine phosphorylation of several kinds of molecules has been shown to be involved in cadherin inactivation (Kinch et al, 1995; Matsuyoshi et al, 1992). We analyzed the tyrosine-phosphorylated proteins (YPPs) using antibodies specifically recognizing phosphotyrosine. No enhancement of YPP signals was 

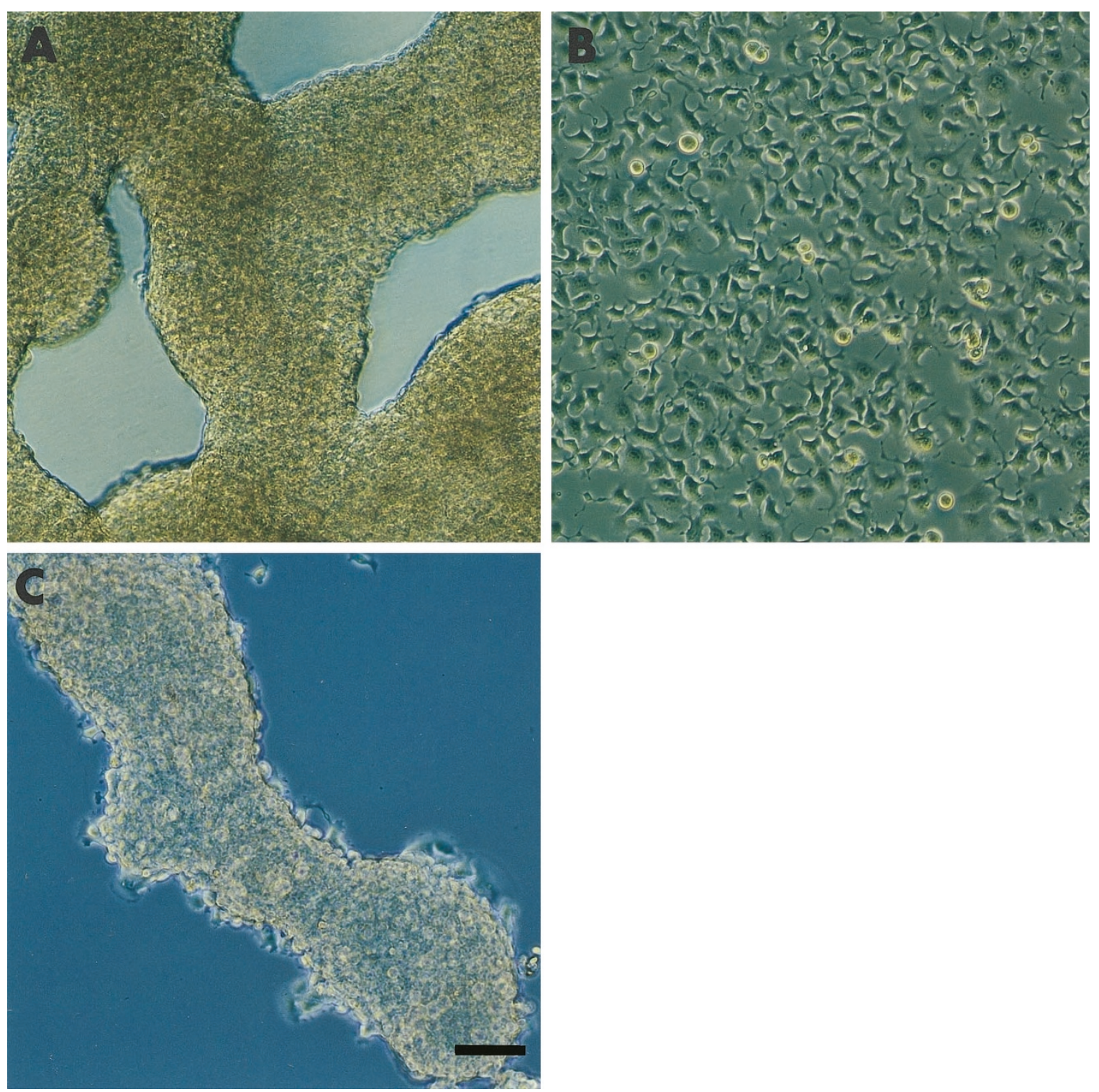

\section{Figure 1.}

Phase-contrast images of KYN-2 cells in vitro. KYN-2 cells were cultured on dishes coated with polyHEMA $(A)$, collagen Type I (B), or collagen Type I in the presence of inhibitory monoclonal antibody against $\beta 1$ and $\beta 5$ integrins. Bar, $100 \mu \mathrm{m}$.

detected in immunoprecipitates collected using antiE-cadherin antibodies (data not shown), or whole cell lysates, but two major YPPs (130 and $60 \mathrm{kd}$ ) were found to be dephosphorylated in whole cell lysates in response to cell-substratum adhesion (Fig. 4A). YPP 130 was not analyzed further in this study. Immunoprecipitation followed by immunoblotting indicated YPP 60 to be c-Src. Furthermore, immunoprecipitates collected using anti-c-Src antibodies contained E-cadherin and $\beta$-catenin, indicating that $\mathrm{c}$-Src associates with the E-cadherin-catenin complex (Fig. 4B). Because $\mathrm{c}-\mathrm{Src}$ is thought to be inactivated by tyrosine phosphorylation in its carboxy-terminal tail (Cooper and Howell, 1993), we speculated that the tyrosine dephosphorylated c-Src in adherent cells was an activated form. Immunoprecipitates collecting anti-cSrc antibodies were analyzed by in vitro tyrosine kinase assay (Fig 4C). Tyrosine kinase activity of c-Src in $\mathrm{KYN}-2$ cells was approximately two-fold higher in adherent cells than in suspended cells. Addition of inhibitory antibodies against $\beta 1$ and $\beta 5$ integrins inhibited tyrosine dephosphorylation of $\mathrm{C}$-Src in adherent cells (Fig. 4D).

\section{Discussion}

E-cadherin is a transmembrane glycoprotein that mediates $\mathrm{Ca}^{2+}$-dependent cell-cell adhesion in a homophilic manner and maintains normal epithelial cell polarity and tissue architecture. Destruction of normal tissue morphology and cell polarity are morphological features of human cancers, and loss of firm cell-cell adhesion has frequently been observed in scatteredtype undifferentiated cancers (Birchmeier and Behrens, 1994) and in the invasive front of highlymetastatic differentiated cancers (Ono et al, 1996). In 

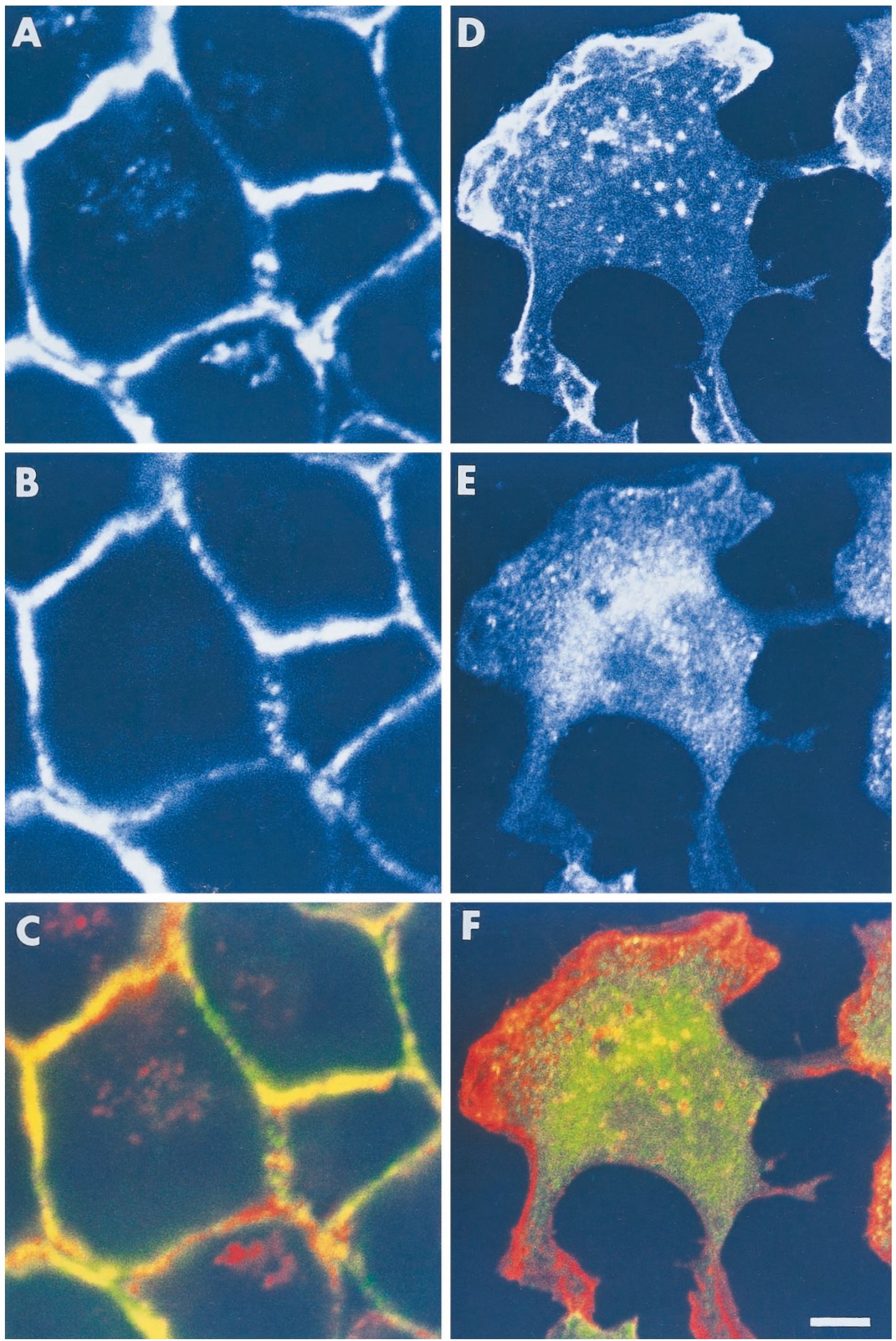

Figure 2.

Confocal fluorescent microscopy showing the localization of E-cadherin and actin filaments in KYN-2 cells. KYN-2 cells were cultured on dishes coated with polyHEMA $(A$ to $C$ ) or on collagen Type I $(D$ to $F$ ). Double fluorescence of actin filaments detected by TRITC-labeled phalloidin $(A, D$ and red in $C$ and $F$ ) and E-cadherin by HECD-1 monoclonal antibody $(B, E$ and green in $C$ and $F)$ is shown. Bar, $5 \mu \mathrm{m}$. 
A

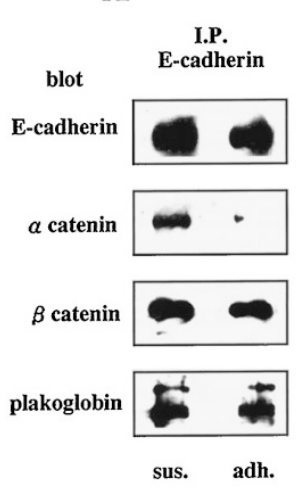

D

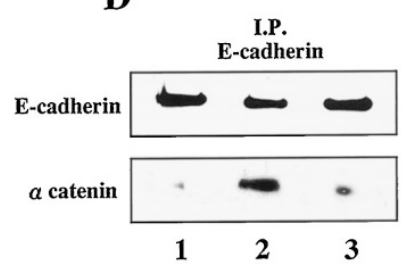

Figure 3.

Association of E-cadherin with catenins in KYN-2 cells. KYN-2 cells were cultured on dishes coated with polyHEMA (sus.) or collagen Type I (adh.). A, E-cadherin and associated proteins collected with anti-E-cadherin antibody and detected using antibodies against E-cadherin, $\alpha$-catenin, $\beta$-catenin, plakoglobin. $B, \alpha$-catenin and associated proteins collected with anti- $\alpha$-catenin polyclonal antibody and detected using anti-E-cadherin or $\alpha$-catenin antibodies. $C$, Expression of E-cadherin, $\alpha$-catenin, $\beta$-catenin, plakoglobin, and p120CAS in whole cell lysates analyzed by immunoblotting. $D$, E-cadherin and associated proteins collected with anti-E-cadherin antibody and detected using anti-E-cadherin or anti- $\alpha$-catenin antibodies. KYN-2 cells were cultured on dishes coated with collagen Type I in the presence of inhibitory monoclonal antibodies against $\beta 1$ and $\beta 5$ integrins (Lane 2) or nonimmunized mouse IgG (Lane 3) or without antibodies (Lane 1). Each result is representative of a total of three experiments.

vitro experiments have demonstrated that E-cadherin-mediated cell-cell adhesion prevents invasiveness of human cancer cells (Behrens et al, 1989; Frixen et al, 1991; Vleminckx et al, 1991), and correlations between E-cadherin expression and poor prognosis in human cancers have been reported (Bringuier et al, 1993; Mattijssen et al, 1993).

Recently, multiple mechanisms have been shown to inactivate the E-cadherin-mediated cell adhesion system in human cancers (Hirohashi, 1998). Genetic alterations of cadherin and catenin molecules have been found in several human cancers (Becker et al, 1994; Kanai et al, 1994; Oda et al, 1994; Oyama et al, 1994; Shimoyama et al, 1992). CpG methylation around the promoter region down-regulates E-cadherin expression (Kanai et al, 1997; Yoshiura et al, 1995). Receptor-type tyrosine kinases, such as c-erbB-2 protein or epidermal growth factor receptor, associate with the E-cadherin-catenin complex and induce tyrosine phosphorylation of $\beta$-catenin after ligand binding, which is followed by cell scattering or invasion (Hazan and Norton, 1998; Hoschuetzky et al, 1994; Ochiai et al, 1994; Shibamoto et al, 1994; Shibata et al, 1996).
$\mathbf{A}$

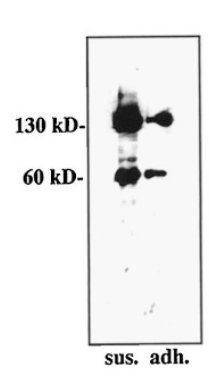

sus. adh.
C

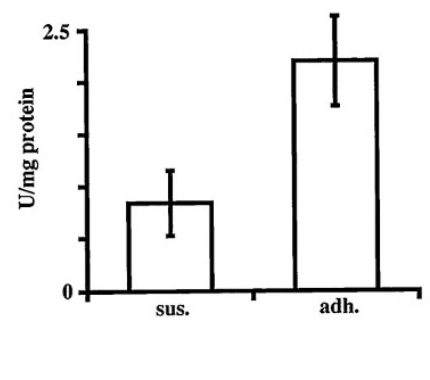

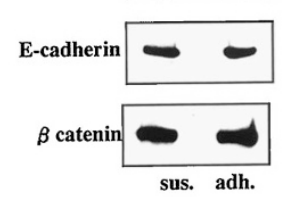

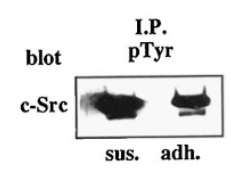

I.P.

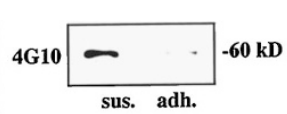

D

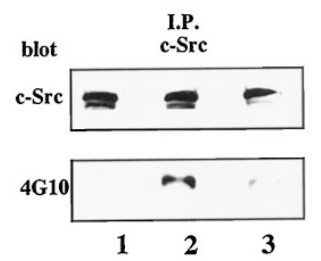

Figure 4.

Association and activation of c-Src in KYN-2 cells. KYN-2 cells were cultured on dishes coated with polyHEMA (sus.) or collagen Type I (adh.). A, Immunoblotting with anti-phosphotyrosine monoclonal antibody of KYN-2 cells. Molecular mass positions ( $\mathrm{kDa}$ ) are shown on the left. $B$, Immunoprecipitates collected with anti-c-Src polyclonal antibody analyzed with anti-c-Src, E-cadherin, $\beta$-catenin, or phosphotyrosine monoclonal antibodies, and immunoprecipitates collected with anti-phosphotyrosine polyclonal antibody analyzed with anti-c-Src monoclonal antibody. C, Tyrosine kinase activity of immunoprecipitates collected with anti-c-Src polyclonal antibody analyzed as described in "Materials and Methods." Data represent mean \pm SD of the results of three studies carried out in triplicate. $D$, Immunoprecipitates collected with anti-c-Src polyclonal antibody analyzed with anti-phosphotyrosine monoclonal antibody. KYN-2 cells were cultured on dishes coated with collagen Type I in the presence of inhibitory monoclonal antibodies against $\beta 1$ and $\beta 5$ integrins (Lane 2) or nonimmunized mouse IgG (Lane 3) or without antibodies (Lane 1). Each result of $A, B$, and $D$ is representative of a total of three experiments.

Hematogenous liver metastasis is thought to consist of a multistep process. Inactivation of the cadherin-mediated cell adhesion system is one step involved in cancer cell detachment from primary tumors and invasion into the stroma. However, E-cadherin is necessary for secondary tumor formation in the liver (Osada et al, 1996). In fact, welldifferentiated colorectal or gastric cancers, which express high amounts of E-cadherin at the point of cell-cell contact, often metastasize to the liver; however, liver metastasis of scattered-type undifferentiated cancers is rare (Duarte and Llanos, 1981; Esaki et al, 1990; Yasui et al, 1997). These observations indicate the importance of transient inactivation of the cadherin system during the process of liver metastasis. Our present data suggest a new mechanism for this transient inactivation.

In KYN-2 cells, loss of cell-cell contact was induced by cell-substratum adhesion in association with 
$\alpha$-catenin dissociation from the E-cadherin-catenin complex. These effects of cell-substratum adhesion could be suppressed by the addition of inhibitory monoclonal antibodies against $\beta 1$ and $\beta 5$ integrins. These findings indicate the existence of cross-talk mechanisms between the E-cadherin and integrin systems: signals from integrin-mediated cellsubstratum adhesion induce reversible inactivation of the cadherin-mediated cell-cell adhesion system in KYN-2 cells. Previous studies have also demonstrated this cross-talk phenomenon in neural crest cells or colon cancer cells (Monier-Gavelle and Duband, 1997; Sakamoto et al, 1996); however, little is known about the molecular mechanisms of this cross-talk. To our knowledge, this is the first report indicating that integrin-mediated cell-substratum adhesion induces $\alpha$-catenin dissociation from the E-cadherin-catenin complex. The level of $\alpha$-catenin in adherent cells was reduced in comparison with suspended cells. The cause of this phenomenon is unknown, but our observation is consistent with a previous report suggesting that post-transcriptional regulation of $\alpha$-catenin expression depends on cadherin function (Nagafuchi et al, 1991).

Dysfunction of the cadherin-mediated cell adhesion system is also induced by the expression of v-Src, a constitutively activated mutant of c-Src (Kellie, 1988; Warren and Nelson, 1987). In v-Src transformed cells, several molecules have been shown to be phosphorylated with tyrosine residues; tyrosine phosphorylation of $\beta$-catenin in particular appears to be associated with the dysfunction of cadherin (Kinch et al, 1995; Matsuyoshi et al, 1992). c-Src is known to be distributed in cytoskeletal complexes in an integrindependent manner (Clark and Brugge, 1993; Miyamoto et al, 1995) and activated by integrin-mediated cell-substratum adhesion (Kaplan et al, 1995). In the KYN-2 system, c-Src was shown to be activated by cell-substratum adhesion in association with tyrosine dephosphorylation and was coimmunoprecipitated with the cadherin-catenin complex. These findings suggest that c-Src is a potential mediator of cross-talk between the integrin and cadherin systems, and that integrin-mediated cell-substratum adhesion induces cadherin dysfunction through c-Src activation. Although we were unable to detect tyrosine phosphorylation of cadherin-catenin complex components, especially $\beta$-catenin, in the adherent cells, a previous report has indicated that tyrosine phosphorylation of $\beta$-catenin is not required for $\mathrm{v}$-Src-induced suppression of cadherin-mediated cell adhesion (Takeda et al, 1995). We think that tyrosine phosphorylation of the other c-Src substrates is involved in this integrinmediated cadherin dysfunction.

Detachment of cancer cells from the primary cancer nest is generally believed to be a key step of invasion and metastasis. The trabecular structure of KYN-2 cells in suspension culture resembles the histological appearance of KYN-2 tumors in the livers of SCID mice. Also KYN-2 cell scattering induced by cellsubstratum adhesion corresponds to the destruction of trabecular structures and infiltrative growth at the periphery of tumors in vivo. We think that loss of cell-cell contact induced by signals from the integrin systems is involved in intrahepatic metastasis of HCC because our previous clinicopathological study showed that intrahepatic metastasis was observed more frequently in cases of HCC with a replacing or infiltrative growth component than in cases without such a component (Kanai et al, 1987).

Our results indicate that E-cadherin dysfunction is induced by signals from integrin-mediated cellsubstratum adhesion in HCC cells and suggest the involvement of cross-talk between the cadherin and integrin systems in intrahepatic metastasis of human HCC. Blockade of integrin function will prevent cancer metastasis by inhibiting not only cancer cell attachment in the target organ but also cadherin inactivation and cell dissociation in the primary cancer nest.

\section{Materials and Methods}

\section{Cell Culture}

The human HCC cell line KYN-2 (Yano et al, 1988) was kindly provided by Dr. M. Kojiro (Kurume University, Kurume, Japan). The cells were cultured in RPMI-1640 medium supplemented with $10 \%$ fetal bovine serum, $100 \mathrm{U} / \mathrm{ml}$ penicillin, and $100 \mu \mathrm{g} / \mathrm{ml}$ streptomycin. To prevent cell attachment to the substratum, the cells were cultured in dishes coated with $20 \mathrm{mg} / \mathrm{ml}$ polyHEMA (Sigma Chemical, St. Louis, Missouri).

\section{Antibodies}

Mouse monoclonal anti-human E-cadherin (HECD-1) (Shimoyama et al, 1989) and anti- $\beta 1$ integrin (INT7) (Fujita et al, 1992) were obtained and characterized as described. Mouse monoclonal anti- $\beta 5$ integrin (P1F6) was purchased from Chemicon (Temecula, California). Mouse monoclonal anti- $\alpha$ catenin, anti- $\beta$ catenin, antiplakoglobin, and anti-p120CAS were purchased from Transduction Laboratories (Lexington, Kentucky). Mouse monoclonal anti-c-Src and antiphosphotyrosine (4G10) and rabbit polyclonal antiphosphotyrosine were purchased from Upstate Biotechnology Inc. (Lake Placid, New York). Rabbit polyclonal anti-c-Src and goat polyclonal anti- $\alpha$ catenin were purchased from Santa Cruz Biotechnology Inc. (Santa Cruz, California).

\section{Immunocytochemistry}

Cells were cultured on glass coverslips coated with 30 $\mu \mathrm{g} / \mathrm{ml}$ collagen Type I, fixed with $4 \%$ paraformaldehyde and $2 \%$ sucrose in phosphate-buffered saline and permeabilized with $0.1 \%$ Triton $\mathrm{X}-100$. Then the cells were treated with $2 \%$ normal swine serum and incubated with primary antibodies overnight at $4^{\circ} \mathrm{C}$, followed by incubation with FITC-labeled secondary antibody (Vector Laboratories, Burlingame, California). Actin filaments were visualized with TRITC-labeled phalloidin (Sigma Chemical). Labeled cells were mounted in Perma Fluor (Lipshow Immunon, Pittsburg, Pennsylvania) and examined with a Zeiss 
LSM410 confocal microscope (Thornwood, New York).

\section{Immunoblotting and Immunoprecipitation}

For immunoblotting of whole cell lysates, cells were lysed for 20 minutes at $4^{\circ} \mathrm{C}$ with RIPA buffer $(50 \mathrm{~mm}$ Tris, pH 8.0, containing $150 \mathrm{~mm} \mathrm{NaCl}, 1 \mathrm{~mm}$ sodium vanadate, $0.5 \%$ sodium deoxycholate, $0.1 \%$ SDS, $1 \%$ Nonidet P-40). Lysates were cleared by centrifugation and protein concentration determined using a Bradford assay (Bio-Rad Laboratories, Hercules, California).

For immunoprecipitation, cells were lysed for 20 minutes at $4^{\circ} \mathrm{C}$ with a buffer containing $10 \mathrm{~mm}$ 4-(2hydroxyethyl)-1-piperazineethanesulfonic acid $(\mathrm{pH}$ 7.4), $150 \mathrm{~mm} \mathrm{NaCl}, 2 \mathrm{~mm} \mathrm{CaCl}_{2}$, 1\% Nonidet P-40, 1\% Triton $\mathrm{X}-100,1 \mathrm{~mm}$ sodium vanadate, $1 \mathrm{~mm}$ phenylmethylsulfonyl fluoride, $2 \mu \mathrm{g} / \mathrm{ml}$ leupeptin, and 2 $\mu \mathrm{g} / \mathrm{ml}$ pepstatin A. Lysates were cleared by centrifugation and the solubilized fractions were immunoprecipitated with the indicated antibodies as described previously (Genda et al, 1999).

Cell lysates and immunoprecipitates were electrophoresed on sodium dodecyl sulfate-polyacrylamide gels and transferred to Immobilon membranes (Millipore, Bedford, Massachusetts). After blocking, the filters were reacted with primary antibody followed by horseradish peroxidase-conjugated secondary antibodies. Peroxidase-labeled bands were visualized using an enhanced chemiluminescence detection system (Amersham International, Buckinghamshire, United Kingdom).

\section{In Vitro Kinase Assay}

Cells were lysed in radio immunoprecipitation assay (RIPA) buffer and immunoprecipitated using anti-c-Src antibodies as described above. Tyrosine kinase activity of immune complexes containing c-Src was determined using TaKaRa Tyrosine Kinase Assay kit (Takara Shuzo, Shiga, Japan) following the manufacturer's instructions.

\section{Acknowledgements}

We thank Dr. M. Kojiro (Kurume University, Kurume, Japan) for his generous gift of KYN-2 cells.

\section{References}

Becker KF, Atkinson MJ, Reich, U, Becker I, Nekarda H, Siewert JR, and Hofler H (1994). E-cadherin gene mutations provide clues to diffuse type gastric carcinomas. Cancer Res 54:3845-52.

Behrens J, Mareel MM, Van Roy FM, and Birchmeier W (1989). Dissecting tumor cell invasion: epithelial cells acquire invasive properties after the loss of uvomorulin-mediated cell-cell adhesion. J Cell Biol 108:2435-2447.

Birchmeier W and Behrens J (1994). Cadherin expression in carcinomas: Role in the formation of cell junctions and the prevention of invasiveness. Biochim Biophys Acta 1198:1126.
Bringuier PP, Umbas R, Schaafsma HE, Karthaus HF, Debruyne FM, and Schalken JA (1993). Decreased E-cadherin immunoreactivity correlates with poor survival in patients with bladder tumors. Cancer Res 53:3241-3245.

Clark EA and Brugge JS (1993). Redistribution of activated pp 60c-src to integrin-dependent cytoskeletal complexes in thrombin-stimulated platelets. Mol Cell Biol 13:1863-1871.

Cooper JA and Howell B (1993). The when and how of Src regulation. Cell 73:1051-1054.

Duarte I and Llanos O (1981). Patterns of metastases in intestinal and diffuse types of carcinoma of the stomach. Hum Pathol 12:237-242.

Esaki Y, Hirayama R, and Hirokawa K (1990). A comparison of patterns of metastasis in gastric cancer by histologic type and age. Cancer 65:2086-2090.

Frixen UH, Behrens J, Sachs M, Eberle G, Voss B, Warda A, Lochner D, and Birchmeier W (1991). E-cadherin-mediated cell-cell adhesion prevents invasiveness of human carcinoma cells. J Cell Biol 113:173-185.

Fujita S, Suzuki H, Kinoshita M, and Hirohashi S (1992). Inhibition of cell attachment, invasion and metastasis of human carcinoma cells by anti-integrin beta 1 subunit antibody. Jpn J Cancer Res 83:1317-1326.

Genda T, Sakamoto M, Ichida T, Asakura H, Kojiro M, Narumiya S, and Hirohashi S (1999). Cell motility mediated by Rho and Rho-associated protein kinase plays a critical role in intrahepatic metastasis of human hepatocellular carcinoma. Hepatology 30:1027-1036.

Hazan RB and Norton L (1998). The epidermal growth factor receptor modulates the interaction of $\mathrm{E}$ - cadherin with the actin cytoskeleton. J Biol Chem 273:9078-9084.

Hirohashi S (1998). Inactivation of the E-cadherin-mediated cell adhesion system in human cancers. Am J Pathol 153: 333-339.

Hoschuetzky H, Aberle H, and Kemler R (1994). Beta-catenin mediates the interaction of the cadherin-catenin complex with epidermal growth factor receptor. J Cell Biol 127:13751380.

Juliano RL and Haskill S (1993). Signal transduction from the extracellular matrix. J Cell Biol 120:577-585.

Kanai T, Hirohashi S, Upton MP., Noguchi M, Kishi K, Makuuchi M, Yamasaki S, Hasegawa H, Takayasu K, Moriyama N, and Shimosato $Y$ (1987). Pathology of small hepatocellular carcinoma. A proposal for a new gross classification. Cancer 60:810-819.

Kanai Y, Oda T, Tsuda H, Ochiai A, and Hirohashi S (1994). Point mutation of the E-cadherin gene in invasive lobular carcinoma of the breast. Jpn J Cancer Res 85:1035-1039.

Kanai Y, Ushijima S, Hui AM, Ochiai A, Tsuda H, Sakamoto $M$, and Hirohashi S (1997). The E-cadherin gene is silenced by $\mathrm{CpG}$ methylation in human hepatocellular carcinomas. Int J Cancer 71:355-359.

Kaplan KB, Swedlow JR, Morgan DO, and Varmus HE (1995). c-Src enhances the spreading of src-/- fibroblasts on fibronectin by a kinase-independent mechanism. Genes Dev 9:1505-1517.

Kellie S (1988). Cellular transformation, tyrosine kinase oncogenes, and the cellular adhesion plaque. BioEssays 8:2529. 
Kinch MS, Clark GJ, Der CJ, and Burridge K (1995). Tyrosine phosphorylation regulates the adhesions of ras-transformed breast epithelia. J Cell Biol 130:461-471.

Matsuyoshi N, Hamaguchi M, Taniguchi S, Nagafuchi A, Tsukita S, and Takeichi M (1992). Cadherin-mediated cellcell adhesion is perturbed by $\mathrm{v}$-src tyrosine phosphorylation in metastatic fibroblasts. J Cell Biol 118:703-714.

Mattijssen V, Peters HM, Schalkwijk L, Manni JJ, van 't Hof-Grootenboer B, de Mulder PH., and Ruiter DJ (1993). E-cadherin expression in head and neck squamous-cell carcinoma is associated with clinical outcome. Int $\mathrm{J}$ Cancer 55:580-585.

Miyamoto S, Teramoto H, Coso OA, Gutkind JS., Burbelo PD, Akiyama SK, and Yamada KM (1995). Integrin function: Molecular hierarchies of cytoskeletal and signaling molecules. J Cell Biol 131:791-805.

Monier-Gavelle F and Duband JL (1997). Cross talk between adhesion molecules: Control of $\mathrm{N}$-cadherin activity by intracellular signals elicited by beta1 and beta3 integrins in migrating neural crest cells. J Cell Biol 137:1663-1681.

Nagafuchi A and Takeichi M (1988). Cell binding function of $\mathrm{E}$-cadherin is regulated by the cytoplasmic domain. EMBO $\mathrm{J}$ 7:3679-3684.

Nagafuchi A, Takeichi M, and Tsukita S (1991). The 102 kd cadherin-associated protein: Similarity to vinculin and posttranscriptional regulation of expression. Cell 65:849-857.

Nagao T, Inoue S, Yoshimi F, Sodeyama M, Omori Y, Mizuta T, Kawano N, and Morioka $Y$ (1990). Postoperative recurrence of hepatocellular carcinoma. Ann Surg 211:28-33.

Nakashima T (1976). Vascular changes and hemodynamics in hepatocellular carcinoma. In: Okuda $\mathrm{K}$ and Peter RL, eds. Hepatocellular carcinoma. New York: Wiley, 169-203.

Ochiai A, Akimoto S, Kanai Y, Shibata T, Oyama T, and Hirohashi S (1994). c-erbB-2 gene product associates with catenins in human cancer cells. Biochem Biophys Res Commun 205:73-78.

Oda T, Kanai Y, Oyama T, Yoshiura K, Shimoyama Y, Birchmeier W, Sugimura T, and Hirohashi S (1994). E-cadherin gene mutations in human gastric carcinoma cell lines. Proc Natl Acad Sci USA 91:1858-1862.

Ono M, Sakamoto M, Ino Y, Moriya $\mathrm{Y}$, Sugihara K, Muto T, and Hirohashi S (1996). Cancer cell morphology at the invasive front and expression of cell adhesion-related carbohydrate in the primary lesion of patients with colorectal carcinoma with liver metastasis. Cancer 78:1179-1186.

Osada T, Sakamoto M, Ino Y, Iwamatsu A, Matsuno Y, Muto T, and Hirohashi S (1996). E-cadherin is involved in the intrahepatic metastasis of hepatocellular carcinoma. Hepatology 24:1460-1467.

Oyama T, Kanai Y, Ochiai A, Akimoto S, Oda T, Yanagihara K, Nagafuchi A, Tsukita S, Shibamoto S, Ito F, Takeichi M, Matsuda H, and Hirohashi S (1994). A truncated beta-catenin disrupts the interaction between E-cadherin and alphacatenin: A cause of loss of intercellular adhesiveness in human cancer cell lines. Cancer Res 54:6282-6287.
Sakamoto M, Ino Y, Ochiai A, Kanai Y, Akimoto S, and Hirohashi S (1996). Formation of focal adhesion and spreading of polarized human colon cancer cells in association with tyrosine phosphorylation of paxillin in response to phorbol ester. Lab Invest 74:199-208.

Shibamoto S, Hayakawa M, Takeuchi K, Hori T, Oku N, Miyazawa K, Kitamura N, Takeichi M, and Ito F (1994). Tyrosine phosphorylation of beta-catenin and plakoglobin enhanced by hepatocyte growth factor and epidermal growth factor in human carcinoma cells. Cell Adhes Commun 1:295305.

Shibata T, Ochiai A, Kanai Y, Akimoto S, Gotoh M, Yasui N, Machinami R, and Hirohashi S (1996). Dominant negative inhibition of the association between beta-catenin and c-erbB-2 by $\mathrm{N}$-terminally deleted beta-catenin suppresses the invasion and metastasis of cancer cells. Oncogene $13: 883-889$

Shimoyama Y, Hirohashi S, Hirano S, Noguchi M, Shimosato Y, Takeichi M, and Abe O (1989). Cadherin cell-adhesion molecules in human epithelial tissues and carcinomas. Cancer Res 49:2128-2133.

Shimoyama Y, Nagafuchi A, Fujita S, Gotoh M, Takeichi M, Tsukita S, and Hirohashi S (1992). Cadherin dysfunction in a human cancer cell line: Possible involvement of loss of alpha-catenin expression in reduced cell-cell adhesiveness. Cancer Res 52:5770-5774.

Takeda T, Nagafuchi A, Yonemura S, Tsukita S, Behrens J, Birchmeier W, and Tsukita S (1995). V-src kinase shifts the cadherin-based cell adhesion from the strong to the weak state and $\beta$-catenin is not required for the shift. J Cell Biol 131:1839-1847.

Vleminckx K, Vakaet L, Mareel M, Fiers W, and van Roy F (1991). Genetic manipulation of E-cadherin expression by epithelial tumor cells reveals an invasion suppressor role. Cell 66:107-119.

Warren SL and Nelson WJ (1987). Nonmitogenic morphoregulatory action of $\mathrm{pp} 60 \mathrm{v}$-src on multicellular epithelial structure. Mol Cell Biol 7:1326-1337.

Yano H, Maruiwa M, Murakami T, Fukuda K, Ito Y, Sugihara $S$, and Kojiro M (1988). A new human pleomorphic hepatocellular carcinoma cell line, KYN-2. Acta Pathol Jpn 38:953966.

Yasui N, Sakamoto M, Ochiai A, Ino Y, Akimoto S, Orikasa A, Kitajima M, and Hirohashi S (1997). Tumor growth and metastasis of human colorectal cancer cell lines in SCID mice resemble clinical metastatic behaviors. Invasion Metastasis 17:259-269.

Yoshiura K, Kanai Y, Ochiai A, Shimoyama Y, Sugimura T, and Hirohashi S (1995). Silencing of the E-cadherin invasionsuppressor gene by $\mathrm{CpG}$ methylation in human carcinomas. Proc Natl Acad Sci USA 92:7416-7419.

Yuki K, Hirohashi S, Sakamoto M, Kanai T, and Shimosato Y (1990). Growth and spread of hepatocellular carcinoma. A review of 240 consecutive autopsy cases. Cancer 66:21742179. 